\title{
Co-Morbidity in Mathematical Learning Disabilities: Rule or Exception?
}

\author{
Annemie Desoete* \\ Department of Clinical Psychology, Research Group Developmental Disorders, University of Ghent, Henri Dunantlaan \\ 2, B-9000 Gent, Belgium
}

\begin{abstract}
This paper presents an overview of two studies in which the co-morbidity of clinical disorders in mathematical learning disabilities (MLD) in elementary school children has been examined. MLD were reported in children with different levels of intelligence. About 54\% did not meet the discrepancy-criterion. The proportions of reading (32\%), spelling (21\%), visuo-spatial (11\%) and language disabilities (10\%) were higher than that found in the general population. The proportion of ADHD (42\%) was also higher than that found in the general proportion. Comorbid heterotypic depression and anxiety rates were $8 \%$ and $6 \%$ respectively. Furthermore a proportion of motor problems (15\%) and ODD problems $(5 \%)$ were reported. This study indicates that co-morbidity with clinical disorders is more a rule than exception in children with MLD. In addition, there may be different patterns of symptoms between genders. Girls more often had an averageintelligent but non-discrepant intelligence profile with less co-morbid problems.
\end{abstract}

\section{INTRODUCTION}

Differences in mathematics between and within individuals are normal. Teachers are expected to cope with learning differences and to adjust their teaching style to the needs of all students. However in some cases these differences appear to be so severe or resistant that they can be considered as characteristics of 'problems' or even 'disabilities'. Most practitioners and researchers currently report that the prevalence of children and adults with mathematical disabilities is not exceptional. Geary (2004) described that between 5\% and $8 \%$ of school-age children have some form of mathematical disabilities. These figures are confirmed in different countries (Dowker, 2005).

The research focus on mathematical learning disabilities still remains limited (Mazzocco \& Myers, 2003). From 2000-2006 only 152 articles on mathematical disabilities (math*disab*) or dyscalculia and 2269 articles on reading disabilities (read*disab*) or dyslexia (or 14.9:1) were cited in Web of science, although the prevalence of both learning disabilities is about (or 1.3:1) the same. Therefore, we agree with Ginsburg (1997) that the problems of children with mathematical disabilities have been underestimated. Although a certain consensus has been reached that problems with learning disabilities are life-affecting and that the impact of poor mathematical skills on employment prospects is even bigger then the influence of poor reading skills (Dowker, 2005), several questions remain unresolved.

One of the unresolved questions is the value of the IQachievement discrepancy in the definition of mathematical learning disabilities. In the debate about the usefulness of IQ-measurement in the assessment of learning disabilities, Siegel (1989) pointed out that the discrepancy model has lead to a great number of children with learning disabilities that are not detected. In line with those findings, Mazzocco

\footnotetext{
*Address correspondence to this author at the Department of Clinical Psychology, Research Group Developmental Disorders, University of Ghent, Henri Dunantlaan 2, B-9000 Gent, Belgium.

E-mail: anne.desoete@Ugent.be.
}

and Myers (2003) more recently stated that the criterion is not sensitive enough to identify all children with mathematical disabilities. A child with a discrepancy between his IQscore and his math achievement may have a mathematical disability (MD), but many children with MD may not meet this discrepancy-criterion. In contrast to the previous researchers, Naglieri and Reardon (1993) argued intelligence to be relevant to the identification of learning disabilities.

Another of the unresolved questions is the co-morbidity rate with other disabilities. Although Shalev (2004) reported that mathematical disabilities in general appear as isolated and specific learning disabilities, much of the clinical evidence is consistent with a lot of co-morbid disabilities (Stock, Desoete, \& Roeyers, 2006). Fletcher and Loveland (1986) found that $81 \%$ of the children with learning disabilities had problems with mathematics and reading, whereas $18 \%$ only had mathematical problems ('pure MD' group) and $1 \%$ failed only in reading tasks. Co-morbidity refers to the co-occurence of one or more diseases or disorders in an individual. The co-occurrence has been termed 'homotypic' co-morbidity, meaning co-morbidity between different members of a general class of disabilities (e.g., reading and mathematical disabilities are both developmental disabilities). 'Heterotypic' co-morbidity is used for the condition where the two disabilities are part of different classes of disabilities, for example mathematical disabilities and depression (Arcelus \& Vostanis, 2005). Another distinction is made between 'concurrent' and 'successive' co-morbidity. Concurrent co-morbidity is that in which two or more disabilities are present at the same time, such as reading and mathematical disabilities. Successive co-morbidity is defined as comorbidity in which disabilities may occur at different times in a person's life, in ways that may or may not be causally related to each other, such as developmental language disorders and learning disabilities (Hall, Lynskey, \& Teesson, 2001). Different methods to assess co-morbidity make study outcomes often difficult to compare. Retrospective studies of children's clinical records are frequently used to assess if there are aspects that might be associated with the children's primary disability. However, such assessments of co- 
morbidity typically pose delicate methodological problems since the available data from the clinical records are often non-homogeneous (Rejno-Habte Selassie, Jennissche, Kyllerman, Viggedal \& Hartelius, 2005; Lacerda \& Ors, 2005).

We here give a brief overview of different disabilities that were reported in co-morbidity with mathematical disabilities. First of all, concurrent homotypic co-morbidity rates of mathematical disabilities and reading disabilities vary from $17 \%$ (Gross-Tsur et al., 1996) to 43\% (Badian, 1983). Besides the high co-morbidity Shalev, Manor, \& Gross-Tsur (1997) found that children with mathematical disabilities in combination with reading disabilities were more profoundly impaired than children with mathematical disabilities alone. A second concurrent homotypic comorbidity that is often reported in children with mathematical disabilities is a writing disability. The co-morbidity of mathematical and writing disabilities is about 50\% (Ostad, 1998; Shalev \& Gross-Tsur, 2001). In addition, the chronicity of the mathematical disability is found to be associated with co-morbid writing problems (Shalev, Manor \& GrossTsur, 2005). Furthermore, studies revealed children with visuo-spatial learning disabilities to have concurrent problems to write number numbers down and to borrow and carry over in subtractions (Forrest, 2004). A successive comorbidity is found in early language disorders. Many children with mathematical learning disabilities appeared to have developmental language disorders (DLD) at preschool age (Manor, Shalev, Joseph \& Gross-Tsur, 2000; Scheiris \& Desoete, 2008; Shalev, 1998; Shalev et al., 2000).

Heterotypic co-morbidity or co occurrences between mathematical and emotional, social or behaviour disturbances are also frequently reported. Concurrent co-morbidity rates of mathematical disabilities and ADHD vary from 20 $\%$ to $60 \%$ (Gross-Tsur et al., 1996; Manor et al., 2001; Monuteaux, Faraone, Herzig, Navsaria \& Biederman, 2005; Lindsay, Tomazic, Levine, \& Accardo 1999). In addition, the gravity of the mathematical disabilities is found to be associated with inattention problems (Shalev, Manor, \& Gross-Tsur, 2005). Children with learning disabilities also were found to exhibit more behaviour problems than children without those disabilities. Schachter, Pless and Bruck (1991) estimated that 43 percent of the children with mathematical disabilities had behaviour problems too. Shalev, Manor, Auerbach and Gross-Tsur (1998) found that the comorbidity of those behavioural problems even was higher for children with persistent mathematical disabilities. Children with mathematical disabilities tended also to have more internalised problems (Osman, 2000; Prior, Smart, Sanson \& Oberklaid, 1999; Shalev, Auerbach, \& Gross-Tsur, 1995; Tsatsanis et al., 1997). However, Shalev and colleagues (1995) found that children with mathematical disabilities did not foster a greater chance in having severe depressions than normal population. They statistically did not exhibit more fears than children without mathematical disabilities.

In summary, the debate on the value of intelligence assessment in mathematical learning disabilities remains unresolved. There is also some controversy about co-morbidity rates for mathematical disabilities. This study attempts to examine both aspects.

\section{Aim and Research Questions}

We investigate in two studies, whether children with mathematical learning disabilities have co-morbid and associated problems. Since it could be so that the academic and co-morbid problems vary, depending on the assessment of co-morbidity, two studies were set up. Study 1 reports a retrospective study of children's clinical records in a child psychiatry and outpatient diagnostic clinic unit, re-examined to establish if there were other disabilities that might be associated with the children's mathematical disabilities. In study 2 children with a clinical diagnosis of mathematical learning disabilities were studied in a non-retrospective open-minded framework, as suggested by Lacerda and Ors (2005), addressing also the contexts. All children were therefore compared with age- and performance-matched subjects in the same schools and in the same immediate mathematical environment and social economic status of the parents.

We had the following research questions: 1. How often do children with a clinical diagnosis of MLD have an average or above average FSIQ? And how is there VIQ, PIQ?

2. How often do children with a clinical diagnosis of MLD have homotypical or heterotypical co-morbidities? Is this more a rule or an exception?

\section{Study 1 \\ METHOD}

\section{Subjects}

The study was approved by the ethics committee prior to completion of the research. Records of elementary school children during the last five years from a university centre of child psychiatry, specialised in developmental and learning disabilities, were retrospectively investigated. Sixty six children out of the initial sample of 200 children fulfilled the criteria for mathematical learning disabilities. They had severe mathematical disabilities, no history of insufficient instruction and persisting problems in spite of mathematics therapy.

From these 66 children randomly 30 full records (17 boys and 13 girls) were selected for further analysis. The mean full-scale IQ of these children was $91.03(S D=7.90)$, the mean verbal IQ was $92.60(S D=8.33)$, the mean performance IQ was $91.63(S D=12.24)$. All children were monolingual Caucasian Dutch speakers. Their age varied, because of different ages of referral to the learning disabilities specialist. The age range of the last assessments by the learning disabilities specialist was 7:0-12:0 (median10:1y).

\section{Psychological and Medical Record}

Information from patient history, speech-language tests, reading tests, mathematics tests, motor function tests, neuro/psychological assessment and observation of behaviour was included. All children were examined by specialists in pediatrics, specialists in child psychiatry, psychologists and therapists specialized in learning disabilities. Reports from medical records included the patient history and medical diagnosis. Heredity for speech-language and learning problems were also reported, together with pre/perinatal problems. The prevalence of speech-language problems at 
Table 1. Verbal and Performance IQ Discrepancies. Number of Children with Co-morbid Symptoms

\begin{tabular}{|c|c|c|c|c|}
\hline & VIQ=PIQ & VIQ<PIQ & VIQ>PIQ & Total \\
\hline Reading problems & 7 & 2 & 1 & $10 / 30$ \\
\hline Language disorder as todler & I & 3 & I & $3 / 30$ \\
\hline Visuo-spatial problems & 2 & l & 5 & $7 / 30$ \\
\hline Attention problems & 7 & 5 & 3 & $15 / 30$ \\
\hline ODD & 2 & I & 1 & $3 / 30$ \\
\hline Anxiety problems & 1 & 1 & 1 & $3 / 30$ \\
\hline
\end{tabular}

school age ( 7 year) or preschool (6 year) were also reported and the need for extra support in school.

On all children, psychological and psychiatric assessment protocols were available. The intelligence of all children was measured. From the psychological record, data relating to full-scale IQ (FSIQ), verbal IQ (VIQ) and performance IQ (PIQ) were taken, as well as all the subtest scores. In cases with several assessments the last occasion was referred to. FSIQ levels between 70 and 84 were classified as below average, 85-115 as average and FSIQ > 115 as above average. Psychological profiles were established using a discrepancy criterion of +/- 1 SD (15 IQ points) for VIQ compared with PIQ. Data on general motor ability and attention problems were drawn from intake, mathematical and psychological records, and profiles were established.

\section{Analysis of Data}

All information referring to co-morbidity and intelligence was collected from the patient history using a data abstraction form. This data abstraction form was tried out on 6 records. These records were not included in the study it self. Data was reviewed by 3 persons reviewing all records. If abstraction was not consistent across data collectors, the records were discussed till every one agreed.

The children were grouped with respect to presence or absence of co-morbid problems

The number of children with co-morbid symptoms, their psychological profiles and other factors are presented in Table 2. Descriptive statistics compared the proportion of comorbid diagnoses with the general population using the test based on binomial distribution. Different multivariate analyses were applied for comparison between groups of children with and without co-morbid problems with respect to the level of intelligence. All the tests were two sided.

\section{RESULTS}

\section{Medical Data}

The proportion of children with mathematical learning disabilities and pre/perinatal problems with preterm birth and low birth weight was $6.6 \%$ ( 1 boy, 1 girl). The problems were preterm birth in one boy and small for gestational age in the girl. A diagnosis of epilepsy had been established in one of the boys $(3.3 \%)$ as opposed to $0.5 \%$ (Kyllerman, O1son, Uvebrant, Mansson, \& Tulinius, 1999) in the general population $(p<.0001)$. In addition $25 \%$ of the children $(n=7)$ had siblings with learning disabilities and $36.7 \%$ of the parents $(n=11)$ had learning problems.

\section{Intelligence Data}

Data relating to the Full Scale IQ (FSIQ) and the discrepancy between VIQ and PIQ are revealed that $76.66 \%$ of the children (8/13 girls, 6/17 boys) had a FSIQ of $>85$. Psychological profiles revealed that in $23.33 \%$ (2/13 girls, 5/17 boys) a discrepancy VIQ<PIQ and in 30\% (3/13 girls, 6/17 boys) an inverse discrepancy VIQ $>$ PIQ was present.

The intelligence scores were further analyzed in this cohort. Children had a FSIQ of $91.03(S D=7.90)$, a verbal IQ score of $92.60(S D=8.33)$ and a Performance IQ score of $91.63(S D=12.24)$. The Mean subtest scores were Information $9.33(S D=2.06)$, Similarities $9.57(S D=2.82)$, Arithmetic $7.47(S D=2.08)$, Vocabulary $9.47(S D=2.13)$, Comprehension $8.87(S D=2.65)$, Digit Span 8.92 ( $S D=2.87)$; Picture Completion $9.70 \quad(S D=2.18)$; Picture Arrangement 9.93 $(S D=2.50)$; Block Design $7.37(S D=3.32)$; Object Assembly 7.37 ( $S D=2.36)$; Coding $10.17(S D=3.35)$; Mazes $\mathrm{M}=9.42$ $(S D=2.98)$; Symbol Search $8.64(S D=3.29)$.

\section{Co-morbidity}

Co-morbidity between one or more factors was found in $29(96.66 \%)$ of the 30 children. The patterns of co-morbidity and the impact on mathematics and intelligence were explored.

In our sample a homotypic co-morbidity of $33.3 \%$ (7 boys, 3 girls) was found for reading disabilities, which is a significantly higher proportion $(p<.0001)$ as opposed to the 2 till $10 \%$ of reading-related cognitive deficits in the general population (Lyon, 1996; Rutter et. al., 2004). Children with or without concurrent reading disabilities did not differ from the children with mathematical disabilities and age adequate reading skills on Verbal and performance IQ $(F(2,27)$ $=0.04 ; p=\mathrm{NS}$ ). 
Table 2. General IQ level. Number of Children with Co-morbid Symptoms

\begin{tabular}{|c|c|c|c|}
\hline & Average & Below Average & Total \\
\hline \hline Reading problems & 7 & 4 & $10 / 30$ \\
\hline Writing problems & 8 & 1 & $3 / 30$ \\
\hline Language disorder as tolder & 2 & 2 & $7 / 30$ \\
\hline Visuo-spatial problems & 5 & 3 & $9 / 30$ \\
\hline Motor problems & 6 & 4 & $15 / 30$ \\
\hline Attention problems & 11 & 1 & $3 / 30$ \\
\hline ODD & 2 & $/$ & $3 / 30$ \\
\hline Anxiety problems & 3 & $/$ & $3 / 30$ \\
\hline Depressive problems & 3 & & \\
\hline
\end{tabular}

In addition, in our dataset $40 \%$ had written expression and spelling problems, which is a significantly higher proportion $(p<.0001)$ as opposed to the $5.75 \%$ of spellingrelated cognitive deficits in the general population (Rosenblum et al., 2003). Eight boys (47.05\%) and four girls $(30.76 \%)$ had a co-morbid diagnosis of spelling deficits. Children with or without homotypic concurrent spelling disabilities did not differ on Verbal and Performance IQ ( $F(2$, 27) $=0.06 ; p=\mathrm{NS}$ ).

Tests from the speech-language record revealed that three children ( 2 boys, 1 girl) were considered to have a deviation in language and speech function as toddler, which is a slightly higher proportion as opposed to the $7.4 \%$ in the general population (Tomblin et al., 1997). None of those children developed a reading or spelling deficit later on. All of them revealed to have a mathematical learning disability later on. Children with or without language problems as toddler did not differ on Verbal and Performance IQ $(F(2,27)$ $=0.07 ; p=\mathrm{NS}$ ).

The proportion of visuo-spatial abnormalities, 7 of 30 investigated $(23.33 \%)$, was significantly higher $(\mathrm{p}<.0001)$ than as opposed to the $0.01 \%$ found in the general population (Forrest, 2004). Four boys (23.53\%) and three girls (23.08\%) had a co-morbid diagnosis of visuo-spatial disabilities. When comparing intelligence $(F(2,27)=3.210 ; p \leq .05)$, the children with visuo-spatial co-morbid problems had a lower Performance IQ $(M=82.43 ; S D=6.90)$ compared with the non visuo-spatial impaired group $(M=94.43 ; S D=12.22)$.

In addition, the pattern of co-morbidity with motor problems was present in six boys and three girls. The proportion of motor skills abnormalities interfering in the actual performances was $30 \%$, which is a significantly higher proportion $(p<.0001)$ as opposed to the proportion $(2-10 \%)$ in the general population (Airaksinen, Michelsson \& Jokela, 2004). Six boys $(35.29 \%)$ and three girls $(23.07 \%)$ had a co-morbid diagnosis of motor deficits. The children with mathematical disabilities and motor skills related deficits did not differ from the children with age-adequate motor skills on verbal and performance IQ $(F(2,27)=2.882 ; p=\mathrm{NS})$.

The proportion of ADHD was 50\%. This proportion was significantly higher $(p<.0001)$ than that found in the general population: 3-9\% (Airaksinen, Michelsson, \& Jokela, 2004; Neuman et al., 2005). Nine boys (52.94\%) and six girls $(46.15 \%)$ in our dataset had a co-morbid diagnosis of ADHD. Children with or without co-morbid diagnosis of $A D H D$ did not differ on VIQ or PIQ (F $(2,27=1.10 ; p=\mathrm{NS})$.

In the sample of children with mathematical learning disabilities, in range with the proportion found in general population (between 2 and 16\%, Mastr \& Wolfe, 2005), 10\% had a co-morbid oppositional defiant disorder $(O D D)$. One boy $(5.88 \%)$ and two girls $(15.38 \%)$ had a co-morbid diagnosis of ODD. No differences were found for verbal or performance IQ $(F(2,27)=0.413 ; p=\mathrm{NS})$ between the group with and without heterotypic co-morbid ODD problems.

The proportion of depression was $10 \%$ ( 2 boys, 1 girl), and higher $(p<.0001)$ than that found in the general population: $3.4 \%$ (Costello et al., 2003). Differences were not found for verbal or performance IQ $(F(2,27)=2.179 ; p=\mathrm{NS})$ between the group with and without depressions.

The proportion of severe anxiety disorders, 3 of 30 investigated $(10 \%$, all boys), was higher $(p<.0001)$ than that found in the general population: $1.4 \%$ (Costello et al., 2003). Children with and without anxiety disorders in our dataset did not differ on verbal or performance IQ $(F(2,27)=0.450$; $p=\mathrm{NS})$.

The VIQ=PIQ profile predominated in children with comorbid reading problems $(70 \%, 7 / 10)$, writing problems $(83.33 \%, 10 / 12)$, and ODD $(66.66 \%, 2 / 3)$. VIQ $>$ PIQ predominated in children with mathematical disabilities and comorbid visuo-spatial problems $(71.43 \%, 5 / 7)$, depressive problems $(60 \%, 3 / 5)$, and motor problems $(55.55 \%, 5 / 9)$. Anxiety problems were common in all groups.

The average intelligence profile predominated (see Table 2). Only the social problems were more pronounced in children with a below average profile.

\section{DISCUSSION}

Psychological profiles revealed in $38.45 \%$ of the girls and $64.7 \%$ of the boys a discrepancy between verbal and performance intelligence was present. Eleven children $(36.66 \%)$ in sample were average intelligent and three chil- 
dren $(10 \%)$ were below-average intelligent without discrepancy between VIQ and PIQ. In line with the results of Mazzocco and Myers (2003) $46.66 \%$ of the children did not meet the quantitative discrepancy-criterion based on the IQ, although they were identified as children with mathematical learning disabilities according to clinical experts.

Our results favor a concurrent homotypic co-morbidity of mathematical disabilities and reading disabilities of $33.33 \%$. A second concurrent homotypic co-morbidity that is often reported in children with mathematical disabilities is writing and spelling disability. The co-morbidity of mathematical and spelling disabilities was $40 \%$. A successive co-morbidity is found in early language disorders. In the sample $10 \%$ of the children with mathematical learning disabilities appeared to have developmental language disorders. Furthermore, our sample revealed that $23.33 \%$ of the children had also visuospatial learning disabilities and $30 \%$ of the sample had severe motor deficits. Heterotypic co-morbidity or co occurrences between mathematical and behaviour disturbances are also reported in the sample. The co-morbidity of mathematical disabilities and ADHD was 50\%. In the sample $10 \%$ had a depression and $10 \%$ had anxiety problems. Depressive children were better on number knowledge than peers without those symptoms.

Findings in this study support the use of a broad assessment to differentiate between different groups of mathematical problem solvers in a continuum from mathematical problem solving with or without co-morbid problems. In addition there may be different patterns of symptoms between genders.

Although we based calculations on notes about the presence of clinically identified symptoms, this study suffers from the shortcomings of any retrospective study, as it uses data that are not uniform. In addition, the severity of problems was often difficult to establish, partly because of the different ages of the children and partly because of a lack of precision in the reported observations. Finally there are certainly limitations due to the proportion of the study. In Study 2 we aim to replicate the co-morbid structure in a non psychiatric setting, with a non-retrospective assessment technique and two control groups. The introduction of control groups aimed to exclude age-and context-related differences in frequency of co-morbid disorders.

We had the following research questions: 1. How often do children with a clinical diagnosis of MLD have an average or above average FSIQ? And how many of the children with a clinical diagnosis of MLD meet the discrepancycriterion? 2. How often do children with a clinical diagnosis of MLD have homotypical or heterotypical co-morbidities? Is this more a rule or an exception? 3. Do children with comorbid problems have lower intelligence scores compared with peers with "pure" mathematical learning disabilities?

\section{STUDY 2}

\section{Method}

\section{Subjects}

The study was approved by the ethics committee prior to completion of the research. Parents received a letter with the explanation of the research and submitted informed consent in order to participate. The subjects belonged to three groups of elementary school children. The first group of children had a 'clinical diagnosis' and were referred to us by participant interdisciplinary teams of psychologists, and therapists skilled in the assessment and treatment of mathematical learning disabilities. Each referred child was screened for inclusion in the study, with written parental permission, based on the following criteria: (1) between eight and ten year old, (2) a clinical diagnosis of learning disabilities and learning problems that could not be explained by the intelligence of children confirmed six months later (3) and an overall below-average school result on mathematics or reading/writing in a testing during this study (4) In addition, only monolingual Caucasian Dutch speakers without histories of insufficient instruction were included as participants. This sample included 72 children (44 boys and 28 girls).

The age-matched control group consisted of 72 elementary school children without a diagnosis of learning disability. These children were matched with the children with mathematics learning disabilities, based upon not more than 1 week difference in date of birth and about the same intelligence (no more than 10 IQ points of difference on TIQ). In addition, the children were school-, gender- and SESmatched on subjects in group 1. The matching on SES was based on the number of years of education of father and mother. To be accepted in the cohort, the mathematics performances had to be rated 4 or 5 on a 7-point performance rating scale $(1=$ very poor, $7=$ very good $)$ by the teacher.

The performance-matched control group consisted of 70 younger elementary school children without a diagnosis of learning disability. The sample was drawn at random, with the permission of the children's parents, from regular elementary classes. The matching was based on their mathematical problem-solving skills on the KRT-R (Baudonck et al., 2006). For this purpose, children with mathematics learning disabilities and this group of younger children performed two tests on domain specific mathematical knowledge (KRT-R normal level and KRT-R for one year older children). Only children were accepted in this study if they could be matched with a child with mathematics learning disabilities and had less than 2 points of difference in performance scores on both tests compared with children with mathematics learning disabilities. In addition, the children were school-, gender-, intelligence- and SES-matched on subjects in group 1. The matching on SES was based on the number of years of education of father and mother. To be accepted in the cohort, the mathematics performances had to be rated 4 or 5 on a 7 -point performance rating scale $(1=$ very poor, 7 $=$ very good) by the teacher.

\section{Measures}

The Kortrijk Arithmetic Test Revision (Kortrijkse Rekentest Revisie, KRT-R) (Baudonck et al., 2006) is a Belgian mathematics test of mental computation (e.g., $129+879=$ _) and of number system knowledge (e.g., add three tens to 61 and you have _). The psychometric value has been demonstrated on a sample of 3,246 Dutch-speaking children. The Arithmetic Number Fact Test (Tempo Test Rekenen, TTR) (de Vos, 1992) is a test on 200 arithmetic number-fact problems (e.g. $5 \times 9=\ldots$ ). The test has been normed for Flanders on 10,059 children. In the present study 
only children rated below the 10 th percentile on the KRT-R or the Arithmetic Number Fact test, with severe and persistent problems diagnosed by skilled therapists were included in the mathematical learning disability (MLD)-group.

The One Minute Test (Een Minuut Test, EMT, Brus \& Voeten, 1999) is a test of reading fluency for Dutch-speaking people, validated for Flanders on 10,059 children, measuring the capacity of children to read correctly as many words as possible. All children were given one minute to read as many words as possible out of the same 116 words. The KLEPEL (Van den Bos et al., 1994) is a test of reading fluency of non-existing words for Dutch-speaking people, validated for Flanders on 899 children, measuring the capacity of children to read correctly as many non-existing words as possible in two minutes. The One Minute Test and the KLEPEL were used for additive information on possible co-morbid reading disorders. Children rating below $10^{\text {th }}$ percentile were considered to have reading difficulties if their difficulties also interfered with academic achievement according to the teacher, with a low or very low score on reading skills on the teacher questionnaire.

The writing skills are assessed with PI-dictee (Geelhoed, Bos, \& Kappers, 1994). In the present study children rating below $10^{\text {th }}$ percentile were considered to have spelling or writing difficulties if their difficulties also interfered with academic achievement according to the teacher, with a low or very low score on spelling skills on the teacher questionnaire.

The Movement Assessment Battery for Children (MABC) (Henderson \& Sugden, 1992; Smits-Engelsman, 1998) was used for additive information on possible co-morbid motor skills disorders. In the present study children rating below $10^{\text {th }}$ percentile were considered to have motor disorders. if their difficulties in gross and fine motor planning, coordination, and control also interfered with academic achievement and daily living activities according to the teacher, with a low or very low score on motor skills on the teacher questionnaire.

The LVS (Dudal, 2000-2003) was developed to assess mathematics in elementary school children. The subtest measurements, was used for additive information on possible co-morbid visuo-spatial disorders. In the present study children rating below $10^{\text {th }}$ percentile were considered to have visuo-spatial difficulties if their difficulties also interfered with academic achievement according to the teacher, with a low or very low score on visuo-spatial skills on the teacher questionnaire.

The DISC-IV (National Institute of Mental Health, Schaffer et al., 2000; Dutch translation, Ferdinand et al, 1998) is a structured diagnostic interview. The following sections were used: DBD's (ADHD, oppositional defiant disorder, conduct disorder), and part of the anxiety disorders section. The DBD (Dutch translation Oosterlaan et al., 2000) was developed to measure externalizing disorders. The questionnaire contains scales for ADHD, ODD and conduct disorder. The Child Behavior Checklist (CBCL) and Teacher's Report Form (TRF) were designed to collect information about children's competencies and problems from parents and teachers (Achenbach \& Rescorla, 2001). Local norms were available for both scales. In the present study children rated by both parents and teachers (i.e., cross-informant) at or beyond $98^{\text {th }}$ percentile on ADHD-relevant behavior (i.e. within the clinical range) and rating very low on attention skills on the teacher rating scale, were considered to have attention deficit. The DBD, DISC-IV and CBCL were used for additive information on possible co-morbid ADHD, ODD, depression, and anxiety disorders.

The teacher questionnaire, which was created for this study, is a rating scale (8-item) questionnaire for teachers on mathematics, reading and spelling performances as well as the motor and visuo-spatial skills, the behavior, attention and intelligence of children (e.g., very low compared to peers (1)/ very good compared to peers (7)). The teacher questionnaire was tested in previous studies in order to determine its construct validity. Test-retest correlations of $.81(p<.01)$ and interrater reliabilities varying between .99 and $1.00(p<$ .01) were found (Desoete \& Roeyers, 2002).

\section{Data Collection}

All subjects were assessed individually outside the classroom setting by skilled therapists who had received 24-hour theoretical and practical training in the assessment of learning and structured interview. All children completed three standardized tests on mathematics, the KRT-R (Baudonck et al., 2006), the TTR (de Vos, 1992), the LVS (Dudal 20002003) as well as the One Minute Test (Brus \& Voeten, 1999), the Klepel (Van den Bos et al., 1994) and PI-dictee (Geelhoed, Bos, \& Kappers, 1994)., on two different days, for about four hours in total. Motor skills were assessed with the M-ABC (Hednerson \& Sugden, 1992). Teachers filled out a questionnaire on reading, writing, motor skills, attention, mathematics and intelligence. Information from writing tests, motor function tests, neuro/psychological assessment and observation of behaviour was included. The intelligence of all children with mathematical learning disabilities was examined with the full scale WISC-III by psychologists specialized in learning disabilities. From the children without learning disabilities a short assessment of intelligence took place (with Block Design, Picture Arrangement, Vocabulary and Similarities). The prevalence of speech-language problems at school age (7 year) or preschool (6 year) were also reported and the need for extra support in school. All parents and teachers of the children were asked to complete the Child Behavior Checklist (CBCL), the DBD (Pelhem et al., 1992; Dutch translation, Oosterlaan et al., 2000), and the Teacher's Report Form (TRF) respectively (Achenbach, 1991). In addition a structured interview took place (DISCIV).

\section{RESULTS}

\section{Intelligence Data}

All children were examined by psychologists and therapists specialized in learning disabilities The prevalence of speech-language at school age (7 year) or preschool (6 year) were also reported and the need for extra support in school. On all children with mathematical learning disabilities, psychological assessment protocols were available. The intelligence of these children was measured, using the WISC-III. From the psychological record, data relating to full-scale IQ (FSIQ), verbal IQ (VIQ) and performance IQ (PIQ) were 
taken, as well as all the subtest scores. FSIQ levels between 70 and 84 were classified as below average, 85-115 as average and FSIQ > 115 as above average. Psychological profiles were established using a discrepancy criterion of +/- 1 SD (15 IQ points) for VIQ compared with PIQ. Data on attention and ODD problems were drawn from intake, mathematical and psychological assessment, and profiles were established.

The intelligence scores on the WISC-III of the children with a clinical diagnosis of mathematical disabilities were analyzed. There was a large difference between children, varying from 75-114 for TIQ, from 68-124 for VIQ and from 72-120 for PIQ. The Mean subtest scores of the sample children with mathematical learning disabilities were Information $8.27(S D=2.35)$, Arithmetics $7.72(S D=1.96)$, Vocabulary $8.06(S D=3.15)$, Comprehension $8.18(S D=2.68)$, Digit Span $7.71(S D=2.58)$, Picture Completion $9.45(S D=3.29)$, Picture Arrangement 7.47 ( $S D=2.74)$, Block Design 8.31 $(S D=2.17)$, Object Assembly $8.63(S D=2.76)$, Coding 9.00 $(S D=1.94)$, Mazes $7.84(S D=2.73)$, Symbol search 10.00 $(S D=2.86)$.

A proportion of $78.37 \%$ (24/29 girls, 34/45 boys) had a FSIQ of $>85$. The Mean Full Scale IQ was $91.11(S D=7.51)$, with a mean Verbal IQ $91.73(S D=9.80)$ and Performance IQ $92.13(S D=8.55)$.

When comparing the profile, $68.91 \%$ of the children (24/29 girls, 27/51 boys) had a VIQ=PIQ. The VIQ < PIQ profile was present in $14.86 \%$ (3/29 girls, 8/45 boys) and $16.21 \%$ (2/29 girls, 10/45 boys) an inverse profile VIQ >PIQ was present.

\section{Co-Morbidity}

Co-morbidity between one or more factors was found in 42 (28/44 boys, $14 / 28$ girls) or in $58.33 \%$ of the 72 children with mathematical learning disabilities which is a significantly higher proportion $(p<.0001)$ as opposed to the comorbidity of $1.38 \%$ ( 1 boy) in the age-matched group and to the $0 \%$ (no children) in the performance-matched group.

In our sample a homotypic co-morbidity of $31.94 \%$ (14/44 boys, 9/28 girls) was found for reading disabilities. Children with or without concurrent reading disabilities did not differ from the children with mathematical disabilities and age adequate reading skills on number knowledge $(F(1$, $69)=0.19 ; p=\mathrm{NS})$ or mental arithmetics $(F(1,69)=0.14$; $p=\mathrm{NS})$ or on Verbal and performance IQ $(F(2,69)=0.96$; $p=\mathrm{NS})$. However they differed on arithmetical facts $(F$ (1, $69)=8.97 ; p \leq .005)$. Children with pure mathematical disabilities were faster on the retrieval of arithmetical facts $(M=20.18 ; S D=21.43)$ than children with combined mathematical and reading disabilities $(M=6.26 ; S D=8.55)$.

In our dataset $12.5 \%$ (7/44 boys, 2/28 girls) had written expression and spelling problems. Children with or without homotypic concurrent spelling disabilities did not differ on number knowledge, mental arithmetics or fact retrieval $(F(3$, $68)=2.08 ; p=\mathrm{NS})$, nor on Verbal and performance IQ $(F(2$, 69) $=0.62 ; p=\mathrm{NS})$.

Tests from the speech-language record revealed that seven children ( 5 boys, 2 girls) were considered to have a deviation in language and speech function as toddler. Five of the children with a deviation in language as toddler developed later on reading and spelling disabilities. One of them developed later on reading disabilities without spelling problems and one had the opposite profile, namely spelling disabilities without reading problems. All of them revealed to have a mathematical learning disability later on. Children with or without language disabilities as toddler did not differ at school age on number knowledge $(F(1,70)=3.12 ; p=\mathrm{NS})$, mental arithmetics $(F(1,70)=0.36 ; p=\mathrm{NS})$, but they did differ on fast fact retrieval $(F(1,70)=4.87 ; p \leq .05)$. Children with or without language disabilities did not differ on Verbal and performance IQ $(F(2,69)=1.22 ; p=\mathrm{NS})$.

The proportion of visuo-spatial abnormalities, 4 of 72 investigated $(5.55 \%)$. Two boys $(4.54 \%)$ and two girls $(7.14 \%)$ had a co-morbid diagnosis of visuo-spatial disabilities. Children with or without co-morbid visuo-spatial capacity problems did not differ on number knowledge, mental arithmetics or fact retrieval $(F(3,68)=1.11 ; p=\mathrm{NS})$. When comparing intelligence $(F(2,69)=6.73 ; p \leq .005)$, the children with visuo-spatial co-morbid problems had a lower Performance IQ $(M=78.75 ; S D=6.23)$ compared with the non visuo-spatial impaired group $(M=92.92 ; S D=8.08)$.

In addition, the pattern of co-morbidity with motor problems was present in six boys. The proportion of motor skills abnormalities interfering in the actual performances was $8.33 \%$ ( $13.62 \%$ boys, $0 \%$ girls). The children with mathematical disabilities and motor skills related deficits did not differ from the children with age-adequate motor skills on number knowledge, mental arithmetics or number fact retrieval $(F(3,68)=1.39 ; p=\mathrm{NS})$. The VIQ of the children with motor problems was higher than the VIQ $(M=101.33$; $S D=15.04)$ of the children without co-morbid motor problems IQ $(M=90.77 ; S D=9.01) ; F(1,70)=6.70 ; p \leq .05)$. No differences were significant on PIQ $(F(1,70)=0.01 ; p=\mathrm{NS})$

The proportion of $A D H D$ was $38.88 \%$. Twenty one boys $(47.72 \%)$ and seven girls $(25 \%)$ in our dataset had a comorbid diagnosis of ADHD. Children with or without comorbid diagnosis of ADHD did differ on number knowledge, mental arithmetics or number fact retrieval ( $F$ (3, $68=0.09 ; p=\mathrm{NS})$, nor on VIQ or PIQ $(F(2,69=1.18 ; p=\mathrm{NS})$.

In the sample $2.77 \%$ had a co-morbid oppositional defiant disorder $(O D D)$. One boy $(2.27 \%)$ and one girl $(3.70 \%)$ had a co-morbid diagnosis of ODD. No differences were found for mental arithmetics, number knowledge or fact retrieval $(F(3,68)=0.22 ; p=\mathrm{NS})$, nor for verbal or performance IQ $(F(2,69)=0.529 ; p=\mathrm{NS})$ between the group with and without heterotypic co-morbid ODD problems.

The proportion of depression was $6.94 \%$ (3 boys, 2 girls). No differences were found for number knowledge, mental arithmetics or fact retrieval $(\mathrm{F}(3,68)=0.351 ; \mathrm{p}=\mathrm{NS})$ or for verbal and performance IQ $(F(3,69)=1.328 ; p=\mathrm{NS})$ between the group with and without depressions.

The proportion of severe anxiety disorders was 3 of 72 investigated ( 2 girls, 1 boy). Children with anxiety disorders in our dataset did not differ on number knowledge, mental or fact retrieval $(F(3,58)=0.743 ; p=\mathrm{NS})$, nor on VIQ or PIQ $(F(2,69)=0.678 ; p=\mathrm{NS})$.

The VIQ=PIQ profile predominated in children with comorbid reading problems $(65.22 \%, 15 / 23)$, writing or spell- 
Table 3. Verbal and Performance IQ Discrepancies. Number of Children with MLD and Co-morbid Symptoms

\begin{tabular}{|c|c|c|c|c|}
\hline & VIQ=PIQ & VIQ $<$ PIQ & VIQ>PIQ & Total \\
\hline Writing problems & 6 & 3 & 0 & $9 / 72$ \\
\hline Language disorder as todler & 4 & 3 & 0 & $7 / 72$ \\
\hline Visuo-spatial problems & 0 & 1 & 3 & $4 / 72$ \\
\hline ODD & 2 & 0 & 0 & $2 / 72$ \\
\hline Anxiety problems & 3 & 0 & 0 & $3 / 72$ \\
\hline Depressive problems & 0 & 2 & 3 & $5 / 72$ \\
\hline
\end{tabular}

Table 4. General IQ Level. Number of Children with MLD and co-morbid Symptoms

\begin{tabular}{|c|c|c|c|}
\hline & Average & Below Average & 5 \\
\hline \hline Reading problems & 18 & 1 & $23 / 72$ \\
\hline Writing problems & 8 & 0 & $7 / 72$ \\
\hline Language disorder as todler & 7 & 1 & $4 / 72$ \\
\hline Visuo-spatial problems & 3 & 1 & $6 / 72$ \\
\hline Motor problems & 5 & 5 & $28 / 72$ \\
\hline Attention problems & 23 & 0 & $2 / 72$ \\
\hline ODD & 2 & 0 & $3 / 72$ \\
\hline Anxiety problems & 3 & 2 & $5 / 72$ \\
\hline Depressive problems & 3 & & \\
\hline
\end{tabular}

ing problems $(66.66 \%, 6 / 9)$, language problems $(57.14 \%$, 4/7), ODD (100\%, 2/2), attention problems $(53.57 \%, 15 / 28)$, anxiety problems $(100 \%, 3 / 3)$ and depressive problems $(60 \% ; 3 / 5)$. The proportion of motor $(66.66 \% ; 4 / 6)$ and visuo-spatial problems predominated in children with a VIQ>PIQ profile. The proportion of language problems $(100 \% ; 3 / 3)$ predominated in children with a VIQ<PIQ profile (see Table 3).

The proportion of average intelligent children with comorbid problems was higher than that of the below-average intelligent children with co-morbid problems (see Table 4).

Co-morbid problems were less common in the two control groups (see Table 5), meaning that the co-morbid problems in the children with mathematical learning disabilities can not be explained by the age or SES and school-context of the children. In the control groups we had one boy or $2.70 \%$ of the performance-matched children (5\% boys, no girls) with co-morbid problems and four boys or $6.66 \%$ of the age-matched children ( $14.28 \%$ boys, no girls) with comorbid problems.

\section{Discussion}

All children in the clinical group had mathematical problems that could not be explained by their intelligence according to the psychologist and to therapists with at least 10 years experience with mathematical learning disabilities. The
TIQ of the children varied from 75-114, often without discrepancy between VIQ and PIQ. Again, in line with the results of Mazzocco and Myers (2003) only $43.05 \%$ of the children ( $52.27 \%$ of the boys and $28.57 \%$ of the girls) did meet the quantitative discrepancy-criterion based on the IQ, although they were identified as children with mathematical learning disabilities according to clinical experts.

In line with the data in study 1 most children with a mathematical disability had no unique mathematics-related deficits. The mathematics-only of 'pure mathematical disabilities' group was $41.66 \%$. There was homotypic co-morbidity with concurrent reading disabilities (31.94\%), writing and spelling disabilities (12.5\%) and with successive language disorders $(9.72 \%)$. There was heterotypic comorbidity with concurrent ADHD (38.88\%), ODD (2.77\%) and anxiety $(4.16 \%)$ or depressive $(6.94 \%)$ behaviour. In the control groups, between $1.38 \%$ and $5.55 \%$ of clinical disorders were present. These findings suggest the high comorbidity rate in mathematical learning disabilities. Especially in boys often co-morbid problems were prominent, whereas girls more often belonged to the "pure" group.

\section{GENERAL DISCUSSION}

In these studies we aimed to investigate the intelligence profile and the co-morbidity in children with mathematical learning disabilities. 


\section{Intelligence Profile}

In our material, mathematical learning disabilities were found in children with different levels of intelligence. Seventy percent of the children had a FSIQ of $>85$. More then half of the children with a clinical diagnosis of mathematical learning disabilities did not meet discrepancy-criterion. In one-fifth of the children a lower Verbal IQ than performance IQ was found. The contrast (VIQ>PIQ), in one fourth was reported. Therefore we do agree with Mazzocoo and Mayers (2003) and Siegel (1989) that the discrepancy-criterion is not sensitive enough, especially in girls, to identify all children with mathematical learning disabilities.

In answer to the question 'do children with co-morbid problems have lower intelligence scores compared with peers with "pure" mathematical learning disabilities', in our material children with co-morbid problems were not less intelligent than children without these problems. Intelligence did not differ in children with and without homotypic language, reading or spelling disabilities, or in children with and without heterotypic ADHD, ODD, anxiety and depressive problems. As expected, children with visuo-spatial problems had a significant lower PIQ than children without those problems in both studies. This indicates that performance intelligence tests measure visuo-spatial qualities. However, the difference relating to the higher VIQ in children with motor problems in study 2 is intriguing and requires further study. Perhaps those children compensate motor 'weak' skills with verbal 'strong' qualities. However this was not shown in study 1 . Further research seems indicated.

\section{Co-morbidity}

Another question is whether learning disabilities are a domain-specific or a more general phenomenon with a lot of co-morbidity with other disabilities. In our material, comorbid problems were found in about four-fifth of the children with mathematical disabilities. In the psychiatric setting an even higher co-morbidity rate was found than in the nonpsychiatric setting.

\section{Homotypic Co-morbidity}

Homotypic successive language and concurrent reading, spelling, and visuo-spatial problems were more pronounced in children with mathematical learning disabilities than in the general population.

Early language disorders as problems (symptoms) were reported in one-tenth of the children with mathematical learning disabilities. Those children seem to outgrow language disorders as toddler and grow into mathematical learning disabilities at school age. In the first study all children developed 'pure' and isolated mathematical disabilities with need for extra mathematical support in school. In the second study five out of seven developed at school age combined mathematics, reading and spelling disabilities. One of them developed mathematical and reading disabilities without spelling problems and one had the opposite profile, namely mathematical and spelling disabilities with age-adequate reading skills. Children with or without language disabilities as toddler (in study 2) differed on fast fact retrieval tasks. This is in accordance with the tentative findings of von Aster (2000) describing semantic memory problems in the verbal subtype of developmental dyscalculia. He originates the acquisition of number-fact knowledge and retrieval strategies in the repeated use of good counting and arithmetic procedures. Children with these kind of mathematical disabilities can not find number fact knowledge accurately so they are delayed in executing procedures. The connection between their language-mathematics problems might also be due to difficulties in the semantic-acoustic aspect of the linguistic domain. Their difficulties experienced in arithmetic might be rooted in verbal deficits (see semantic memory subtype Geary, 2004). However, this is not in accordance with the fact that all children in study 1 did not have reading or spelling problems. Perhaps this is due to the fact that the data of retrospective studies are not uniform or to the fact that clinical symptoms varied with age. Further research seems indicated.

In line with the proportion found by Ostad (1998) and Shalev and Gross-Tsur (2001), one-third of the children had a mixed mathematical-reading disability. All of these children had hereditary learning problems. Children with combined disabilities were also slower on the retrieval of arithmetical facts than children with 'pure' mathematical disabilities. Generally, in children with mathematical disabilities arithmetic facts are often not automatized, so simple arithmetic problems have to be calculated. This in turn makes that much time is needed in order to give an answer. Therefore perhaps a more 'global' problem with retrieval from long term memory can be a possible factor behind the combined mathematics and reading problems.

Homotypic concurrent spelling problems were reported among one-fifth of the sample. Higher proportions were found in the study by Ostad (1998) and Shalev and GrossTsur (2001). In our material, children with co-morbid spelling disabilities did not have more pronounced mathematical problems as opposed to children without spelling problems.

Furthermore visuo-spatial problems were common in about one-tenth of the children. This profile is in line with a pattern of mathematical disabilities that is often described in literature containing a conjunction of visuo-spatial disabilities in the arithmetic domain. This subtype is characterized by problems with insight in and notions of space. Those deficits are typically translated in difficulties in situating numbers on the number line, shuffling numbers in big figures and difficulties in the understanding of geometry (Shalev, 2004).

Motor problems were reported among about one third of the children with mathematical learning disabilities in a child-psychiatric setting and among about one tenth of the sample children in a non-psychiatric diagnostic setting. For motor problems the non-psychiatric proportion is not more pronounced than in those in the general population reported by Kadesjo and Gillberg (1999).

\section{Heterotypic Co-morbidity}

Heterotypic ADHD was more pronounced in children with mathematical learning disabilities than in the general population. In line with the research of Gross-Tsuer et al.. (1996) and Manor et al., (2001), in our material a heterotypic co-morbidity rate of about two-fifth was reported for ADHD. There appeared to be a direct no correlation between the be- 
havioural phenomena and the mathematical disabilities in the sense that children, who initially had a co-morbid ADHD disability, did not manifest more severe number knowledge, mental arithmetics or number fact retrieval dysfunctions than children who suffered 'pure' mathematical disabilities.

The proportion of co-morbid problems also depended on the setting and on whether the diagnosis was given in a child-psychiatric (study 1) or in a regular multidisciplinary non-psychiatric (study 2) setting. Problems were more pronounced than in the general population among the children in the child-psychiatric setting.

Children with mathematical disabilities in the childpsychiatric datasets tended also to have more internalised (depression and anxiety) and externalised (ODD) problems. However, in contrast with the findings of Shalev and colleagues (1995), also in a non-psychiatric sample the proportion of persisting problems with depression and anxiety was bit higher than that found in the general population (Essau, Conradt, \& Petermann, 1999; Costello et al., 2003).

\section{Gender}

In our material, more then four-fifth of the girls (and only two-third of the boys) had a FSIQ of > 85. However, especially girls with a clinical diagnosis of mathematical learning disabilities did often not meet the discrepancy-criterion. In one-seventh of the girls a lower Verbal IQ than performance IQ was found. In contrast, in one-sixth of the girls an inverse profile (higher Verbal IQ than performance IQ) was reported. In one-fourth of the boys a lower VIQ than PIQ was found. In contrast, in one-third of the boys an inverse profile was reported.

In our material, more concurrent co-morbid homotypic problems were found in boys. About $11 \%$ of the boys (and $7 \%$ of the girls) were considered to have a deviation in language and speech function as toddler. Reading, writing and motor problems were present in about one-third, one-fourth and one-fifth respectively of the boys. Those problems were present in about $29 \%$, one-eight and $7 \%$ respectively of the girls in our dataset. No significant gender differences were found for the proportion of concurrent homotypic visuospatial difficulties and for the proportion of concurrent heterotypic ADHD, ODD, depression and anxiety problems.

These results might indicate a different pattern of symptoms between genders. Girls seem more often to have an average-intelligent but non-discrepant intelligence profile with less co-morbid problems.

\section{Methodological Considerations}

The results of these studies should be interpreted with care since comparisons to general population suppose that outcome being assessed is measured in the same manner. It is also possible that ADHD is a confounder of mathematical learning disabilities. Given that the population is taken from individuals who have documented disabilities, the higher ADHD percent is not surprising. In addition, co-morbidity might be age-dependent. Moreover, depending on the particular nature of the mathematical task presented, intelligence may have a differential influence. Furthermore, the research needs full explanation from more applied research on different age and intelligence groups. Finally, the first study suffers from the shortcomings of any retrospective study, as it uses data that are not uniform. However, we have not made any calculations relating to details but have only based them on notes about the presence of clinically identified co-morbid disabilities. The number of individuals is low in study 1 , resulting in a lack of power. However many of the results in study 2 agree with what has previously been found, thereby adding to the strength. In addition, a nonretrospective assessment with a larger number of subjects was used in the second study.

Although the generalization of the results from 102 cases is severely limited, the results indicate that co-morbidity is more rule then expection, stressing the importance of assessing reading and writing skills, visuo-spatial and motor capacity deficits, ADHD, DCD, as well as depressive, anxiety symptoms in people who are admitted with mathematical disabilities in a child psychiatric or regular multidisciplinary setting. The lack of correct and complete diagnoses may negatively influence the choice of appropriate care. Early assessment of successive or concurrent co-morbid disabilities might have a positive influence on the psychological development and socialization process in people with mathematical disabilities and/or for example ADHD or reading disabilities.

To conclude, mathematical learning disabilities were reported in children with different levels of intelligence. More than half of the children with a clinical diagnosis of mathematical learning disabilities did not meet the discrepancycriterion. Analyses revealed high proportions of successive and concurrent homotypic and heterotypic disabilities. There can be little dispute that the presence of co-morbidity poses a serious challenge to existing classification systems of psychopathology This study indicates that it is important to take into account co-morbidity in children with mathematical learning disabilities.

\section{References}

Achenbach, T., \& Rescorla, L. (2001). Manual for the ASEBA School-Age Forms \& Profiles.

Burlington, VT: University of Vermont, Research Centre for Children, Youth \& Families

Araksinen, E.M., Michelsson, K., \& Jokela, V. (2004). The occurence of inattention, hyperactivity, impulsivity and coexisting symptoms in a population study of 471 6-8 year old children based on the FTF (five to fifteen) questionnaire. European Child \& Adolescent psychiatrie. Suppl.3, 13, 23-30.

Arcelus, J., \& Vostanis, P. (2005). Psychiatric comorbidity in children and adolescents. Current opinion in psychiatry, 18, 429-434.

Badian, N. (1999). Reading disability defined as a discrepancy between listening and reading comprehension: A longitudinal study of stability, gender differences, and prevalence. Journal of learning disabilities, 32, 138-148.

Baudonck, M., Debusschere, A., Dewulf, B., Samyn, F., Vercaemst, V., \& Desoete, A. (2006). De Kortrijkse Rekentest Revision KRT-R. [The Kortrijk Arithmetic Test Revision KRT-R]. Kortrijk: CAR Overleie.

Brus, B.T., \& Voeten, M.J.M. (1999). Een Minuut Test (translation: One Minute Test). Lisse: Swets \& Zeitlinger.

Costello, E., Mustillo, S., Erkanli, A., Keeler, G., \& Angold, A. (2003). Prevalence and development of psychiatric disorders in childhood and adolescents. Archives of general psychiatry, 60, 837-844.

Davenport, P., \& Howe, C. (1999). Conceptual gain and successful problem-solving in primary school mathematics. Education studies, 25, 55-78.

De Ridder-Sluiter, J.G., \& van der Lem, G.J. (1995). Vroegtijdige onderkenning van communicatieve ontwikkelingsstoornissen. [Early de- 
tection of communication disorders]. Stem, spraak- en taalpathologie, 4 (2), 103-114.

Desoete, A., \& Roeyers, H. (2002). Off-line metacognition. A domainspecific retardation in young children with learning disabilities? Learning Disability Quarterly, 25, 123-139.

Desoete, A., Roeyers, H., \& De Clercq, A. (2004). Children with mathematics learning disabilities in Belgium. Journal of learning disabilities, $37,50-61$.

De Vos, T. (1992). Test voor het vaststellen van het rekenvaardigheidsniveau der elementaire bewerkingen (automatisering) voor het basis en voortgezet onderwijs. Handleiding [Test to determine the mathematics ability level for elementary operations (automatization) in primary and secondary education: Manual]. Nijmegen, the Netherlands: Berkhout.

Dowker, A. (2005). Individual differences in arithmetic. Implications for psychology, neuroscience and education. Hove, UK: Psychology Press.

Dudal, P. (2000-2003). Leerlingvolgsysteem. Wiskunde. Toetsen 1-4. Leuven: Garant.

Essau, C., Conradt, J., \& Petermann, F. (1999). Frequency and comorbidity of generalized anxiety disorder -Results from the Bremer Adolescent Study. Nervenheilkunde, 18, 46-51.

Ferdinand, R.F., Van der Ende, J., \& Mesman, J. (1998). Diagnostic Interview Schedule for children, DISC-IV. Nederlandse vertaling [Dutch translation]. Unpublished manuscript. Sophia Kinderziekenhuis: Rotterdam.

Fletcher, J.M., \& Loveland, K.A. (1986). Neuropsychology of arithmetic disabilities in children. Focus on Learning Problems in Mathematics, 8, 23-40.

Forrest, B. (2004). The utility of math difficulties, internalized psychopathology, and visuo-spatial deficits to identify children with the nonverbal learning disability syndrome: Evidence for a visualspatial disability. Child Neuropsychology, 10, 129-146.

Fuchs, L. S., \& Fuchs, D. (2002). Mathematical problem-solving profiles of students with mathematics disabilities with and without comorbid reading disabilities. Journal of learning disabilities, 35, 563-57.

Fuchs, L. S., Compton, D. L., Fuchs, D., Paulsen, K., Bryant, J. D., \& Hamlett, C. L. (2005). The prevention, identification, and cognitive determinants of math difficulty. Journal of Educational Psychology, 97, 493-513.

Gadow, K., Nolan, E., Sprafkin, J. , \& Schwartz, J. (2002). Tics and psychiatric comorbidity in children and adolescents. Developmental medicine and child neurology, 44, 330-338.

Geary, D. C. (2004). Mathematics and learning disabilities. Journal of learning disabilities, 37, 4-15.

Geary, D.C., Saults, S.J., Liu, F., \& Hoard, M.K. (2000). Sex differences in spatial cognition, computational fluency, and arithmetical reasoning. Journal of Experimental child psychology, 77, 337-353.

Geelhoed, J.W., Bos, W.N., \& Kappers, E.J. (1994). PI dictees. Paedologisch Instituut:. Amsterdam

Gersons-Wolfsenberger, D.C.M., \& Ruijssenaars, W. (1997). Definition and treatment of dyslexia: a report by the committee on dyslexia of the Health council of the Netherlands, Journal of learning disabilities, 30, 209-213.

Gillberg C. (2003) Deficits in attention, motor control and perception: a brief review. Archives of Disease in Childhood, 88, 904-910.

Ginsburg, H. P. (1997). Mathematics learning disabilities: a view from developmental psychology. Journal of learning disabilities, 30, 2033.

Gross-Tsur, V., Manor, O., \& Shalev, R. S. (1996). Developmental dyscalculia: prevalence and demographic features. Developmental Medicine and Child Neurology, 38, 25-33.

Henderson,S.E., \& Sugden D.A. (1992) Movement Assessment Battery for Children: Manual. London: Psychological Corporation.

Hall, W., Lynskey, M., \& Teesson, M. (2001). What is comorbidity and why does it matter? In M. Teesson \& L. Burns (Eds.), National Drug Strategy: National Comorbidity Project. (pp. 11-12).National Drug and Alcohol Research Center. University of NSW: Sydney .

Kadesjo, B., \& Gilberg, C. (1999). Developmental coordination disorder in Swedish 7-year -old children. Journal of American academy of child and adolescent psychiatry, 38, 820-828.

Hammill, D. D. (1990). On defining learning disabilities: An emerging consensus. Journal of learning disabilities, 23, 74-84

Kamphaus, R. W., Petosky, M. D., \& Rowe, E. W. (2000). Current trends in psychological testing of children. Professional Psychology: Research and Practice, 31, 155-164.
Katusic, S., Colligan, R., Barbaresi, W., Schaid, D., \& Jacobson, S. (2001). Incidence of reading disability in a population-based birth cohort 1976-1982, Rochester, Minn. Maya clinic proceedings, 76, 10811092.

Kavale, K. A., \& Forness, S. R. (2000). What definitions of learning disability say and don't say. A critical analysis. Journal of learning disabilities, 33, 239-256.

Kyllerman, M.., Olsson, I., Uvebrant, P., Mansson, J.E., \& Tulinius, M. (1999). Neurology in T. Lindeberg, H. Lagerkrantz (Eds.), Barnmedicin. Studentlitteratur. Lund.

Lacerda, F., \& Ors, M. (2005). Interdisciplinary and prospective studies necessary to increase insight into developmental language disorders. Commentaries, 399-401.

Lanzi, G., Zambrino,C., Termine, C., Palestra, M. Genevra, O., Orcesi, S. Manfredi, P., \& Beghi, E. (2004). Prevalence of tic disorders among primary school students in the city of Pavia, Italy. Archives of disease in childhood, 89, 45-57.

Lewis, C., Hitch, G. J., \& Walker, P. (1994). The prevalence of specific arithmetic difficulties and specific reading difficulties in 9- to 10 year old boys and girls. Journal of Child Psychology and Psychiatry, 35, 283-292.

Light, G. J., \& DeFries, J. C. (1995). Comorbidity for reading and mathematics disabilities: Genetic and environmental etiologies. Journal of Learning Disabilities, 28, 96-106.

Lindsay, L., Tomazic, T., Levine, M.D., \& Accardo P.J. (1999). Annotation. Impact of attentional dysfunction in dyscalculia. Developmental Medicine and Child Neurology, 41, 639-342.

Lyon, G. (1996). Learning disabilities. Future of children, 6, 54-76.

Mastr, E.J., \& Wolfe, D.A. (2005). Abnormal child psychology. Belmont, CA, Wadsworth: Thomson Learning.

Manor, O., Shalev, R. S., Joseph, A., \& Gross-Tsur, V. (2000). Arithmetic skills in kindergarten children with developmental language disorders. European Journal of Paediatric Neurology, 5, 71-77.

Maughan, B., Rowe, R., Messer, J., Goodman, R., \& Meltzer, H. (2004). Conduct disorder and oppositional defiant disorder in a national sample: developmental epidemiology. Journal of child psychology and psychiatry, 45, 609-621.

Mazzocco, M. M. M., \& Myers, G. F. (2003). Complexities in identifying and defining mathematics learning disability in the primary schoolage years. Annals of Dyslexia, 53, 218-253.

McGlaughlin, S.M., Knoop, A.J., \& Holliday, G.A. (2005). Differentiating students with mathematics difficulty in college: mathematics disabilities vs. no diagnosis, Learning Disability Quarterly, 28, 223232.

Meltzer, L., Roditi, B., Houser, R.F., \& Perlman, M. (1998). Perceptions of academic strategies and competence in students with learning disabilities. Journal of learning disabilities, 31, 437-451.

Monuteaux, M. C., Faraone, S. V., Herzig, K., Navsaria N., \& Biederman, J. (2005) ADHD and dyscalculia: Evidence for independent familial transmission. Journal of Learning Disabilities, 38, 86-93.

Nabuzoka, D., \& Smith, P. (1993). Sociometric status and social behavior of children with and without learning difficulties. Journal of Child Psychology and Psychiatry and Allied Disciplines, 34, 1435-1448.

Naglieri, J. A., \& Reardon, S. M. (1993). Traditional IQ is irrelevant to learning disabilities - Intelligence is not. Journal of learning disabilities, 26, 127-133.

Neuman, R., Sitdhiraksa, N., Reich, W., Ji, T., Joyner, C., Sun, L., \& Todd, R. (2005). Estimation of the prevalence of DSM-IV and latent class-defined ADHD subtypes in a populations-based sample of child and adolescent twins. Twins research and human genetics, 8, 392-401.

Nolen-Hoeksema, S., \& Girgus, J. (1994). The emergence of gender differences in depression during adolescence. Psychological bulletin $115,424-443$.

Oosterlaan, J., Scheres, A., Antrop, I., Roeyers, H., \& Sergeant, J.A. (2000). Vragenlijst voor Gedragsproblemen bij Kinderen (VvGK). Nederlandse bewerking van de Discruptive Behavior Disorders Rating Scale [Dutch translation of the Disruptive Behavior Disorders Rating Scale]. Lisse, The Netherlands: Swets \& Zeitlinger.

Osman, B. B. (2000). Learning disabilities and the risk of psychiatric disorders in children and adolescents. In Greenhill, L. L. (Ed.), Learning disabilities. Implications for psychiatric treatment. Washington, D.C: American Psychiatric Press, Inc.

Ostad, S. A. (1998). Developmental differences in solving simple arithmetic word problems and simple number-fact problems: A comparison of 
mathematically normal and mathematically disabled children. Mathematical Cognition, 4, 1-19.

Pelham, W., Gnagy, E.M., Greenslade, K.E., \& Milich, R. (1992). Teacher ratings of DSM-III R symptoms for the disruptive behavior. Journal of the American Academy of Child and Adolescent Psychiatry, 31, $210-218$

Prior, M., Smart, D., Sanson, A., \& Oberklaid, F. (1999). Relationships between learning difficulties and psychological problems in preadolescent children from a longitudinal sample. Journal of the American Academy of Child and Adolescent Psychiatry, 38, 429436.

Rejno-Habte Selassie, G., Jennische, M., Kyllerman, M., Viggedal, G., \& Hartelius, L.(2005). Comorbidity in severe developmental language disorders: Neuropediatric and psychological considerations. Acta Paediatrica, 94, 471-478.

Rock, E., Fessler, M., \& Church, R. (1997). The Concomitance of Learning Disabilities and Emotional/Behavioral Disorders: A Conceptual Model. Journal of Learning Disabilities, 30, 245-263.

Rosenblum, S., Parush, S., Epstain, L., \& Weiss, P. (2003). Process versus product evaluation of poor handwriting among children with developmental dysgraphia and ADHD. In Teulings, H. L. \&. Van Gemmert, A. W. A. (2003). Proceedings of the 11th Conference of the International Graphonomics Socity. USA; Scottsdale Arizona. 169-173.

Rutter, M., Caspi, A., Fergusson, D., Horwood, L.J., Goodman, R., Maughan, B., Moffitt, T.E., Meltzer, H., \& Carroll, J. (2004). Sex differences in developmental reading disability. New findings from 4 epidemiological studies. Journal of the American Medical Association, 291, 2007-2012.

Schachter, D., Pless, I., \& Bruck, M. (1991). The prevalence and correlates of behavior problems in learning disabled children. Canadian Journal of Psychiatry - Revue Canadienne de Psychiatrie, 36, 323-331.

Scheiris, J., \& Desoete, A. (2008). De prevalentie van enkele specifieke ontwikkelings- en gedragsstoornissen en hun comorbiditeit [The prevalence of some specific developmental and behavioural disorders and their co-morbidity]. Signaal, 62, 4-14.

Shaffer, D., Fisher, P., Lucas, C.P., Dulcan, M.K., \& Schwab-Stone, M.E. (2000). NIMH Diagnostic Interview Schedule for Children Version IV (NIMH Disc-IV): Description, differences from previous versions, and reliability of some common diagnoses. Journal of the American Academy of Child and Adolescent psychiatry, 39, 28-38.

Shalev, R. (1998). Developmental dyscalculia. In: Perat, M. J. (Ed.), New Developments in Child Neurology (pp. 635-641). Bologna: Monduzii Editore.
Shalev, R. S. (2004). Developmental dyscalculia. Journal of Child Neurology, 19, 765-771.

Shalev, R. S., Auerbach, J., \& Gross-Tsur, V. (1995). Developmental dyscalculia, behavioural and attentional aspects: A research note. Journal of Child Psychology and Psychiatry, 36, 1261-1268.

Shalev, R. S., Auerbach, J., Manor, O., \& Gross-Tsur, V. (2000). Developmental dyscalculia: prevalence and prognosis. European Child and Adolescent Psychiatry, 9, II59-II64.

Shalev, R. S., Manor, O., Auerbach, J., \& Gross-Tsur, V. (1998). Persistence of developmental dyscaculia: What counts? Results from a three year prospective follow-up study. Journal of Pediatrics, 133, 358-362.

Shalev, R., Manor, O., \& Gros-Tsur, V. (2005). Developmental dyscalculia: a prospectieve six-year follow-up. Developmental Medicine and Child Neurology, 47, 121-125.

Shaywitz, S., \& Shaywitz, B. (2004). Reading disability and the brain. Educational leadership, 61, 6-11.

Siegel, L. S. (1989). IQ is irrelevant to the definition of learning disabilities. Journal of Learning Disabilities, 22, 469-478.

Smits-Engelsman, B. (1998) Movement Assesment Battery for Children. Manual. Lisse: Swets.

Stock, P., Desoete, A., \& Roeyers, H. (2006). Focussing on Mathematical Disabilities: A Search for Definition, Classification and Assessment. Soren V. Randall (Ed.), Learning Disabilities New Research. (pp. 29-62). Hauppage: New Research Nova Science.

Tomblin, J.B., Records, N.L., Buckwalter, P., Zhang, X.Y., Smith, E., \& O'Brien, M. (1997). Prevalence of specific language impairment in kindergarten children. Journal of Speech Language and Hearing Research, 40, 1245-1260.

Tsanasis, K., Fuerst, D., \& Rourke, B. (1997). Psychosocial Dimensions of Learning Disabilities: External Validation and Relationship with Age and Academic Functioning. Journal of Learning Disabilities, 30, 490-502.

Van den Bos, K.P., Spelberg, H.C.L., Scheepstra, A.J.M., \& de Vries, J.R. (1998). De Klepel pseudowoordentest. Lisse: Swets \& Zeitlinger.

Verhulst, F., Koot, J., Akkerhuis G., \& Veerman, J. (1990). Practical Manual for the CBCL. Assen: Van Gorcum.

von Aster, M. (2000). Developmental cognitive neuropsychology of number processing and calculation: varieties of developmental dyscalculia. European Child and Adolescent Psychiatry, 9, II/41-II/57.

Winne, P.H., \& Perry, N.E. (2000). Measuring self-regulated learning. In M. Boekaerts, P.E. Pintrich,\& M. Zeidner (Eds.), Handbook of selfregulation (pp. 531-566). San Diego: Academic Press.

(C) Annemie Desoete; Licensee Bentham Open.

This is an open access article distributed under the terms of the Creative Commons Attribution License (http://creativecommons.org/license/by/2.5/), which permits unrestrictive use, distribution, and reproduction in any medium, provided the original work is properly cited. 